\title{
Avaliação Microbiológica de Água de Bebedouros Das Unidades de Produção de Frutos no Vale do Jaguaribe - $\mathrm{Ce}$
}

Francisco Jorge Nogueira de Moura (I), Germana Conrado de Souza (I), Mayra Cristina Freitas Barbosa (I), Elisabeth Mariano Batista (I), Mayara Salgado Silva (I), Hyngrid Rannielle de Oliveira Gonsalves (I), Ana Carmem de Oliveira Lima (I), Monique Ellen Torres da Silva (I), Zulene Lima de Oliveira (I), Auriana de Assis Regis (I)

(I) IFCE - Instituto Federal de Educação, Ciência e Tecnologia do Ceará (Rua Estevam Remígio, 1145, Centro, Limoeiro do Norte, Ceará CEP 62930-000.)

\section{Resumo}

Durante as atividades de campo, todo trabalhador deve ter fácil acesso à água potável de qualidade e em quantidade suficiente para suprir suas necessidades, porém muitas vezes não é o que de fato acontece, o que torna os colaboradores susceptíveis às doenças de veiculação hídrica. Este trabalho teve como objetivo avaliar a qualidade microbiológica da água de bebedouros nas unidades de produção de frutos no Vale do Jaguaribe Ceará. Para realização deste trabalho, foram coletadas 10 amostras, sendo uma de cada unidade de produção, na quantidade aproximada de $100 \mathrm{~mL}$ em frascos estéreis, acondicionados em embalagens isotérmicas e encaminhados imediatamente para o Laboratório de Microbiologia do IFCE - Campus Limoeiro do Norte - CE, onde foram determinadas a presença de coliformes totais e coliformes termotolerantes. $\mathrm{O}$ procedimento foi realizado, de acordo com a Portaria no 2914 de 2011 do Ministério da Saúde, que dispõe sobre os procedimentos de controle e de vigilância da qualidade da água para consumo humano e seu padrão de potabilidade. A metodologia utilizada nos experimentos seguiu o recomendado pela American Public Heath Association. Para a avaliação microbiológica, foi

\footnotetext{
Referência:

Francisco Jorge Nogueira de Moura, Germana Conrado de Souza, Mayra Cristina Freitas Barbosa, Elisabeth Mariano Batista, Mayara Salgado Silva, Hyngrid Rannielle de Oliveira Gonsalves, Ana Carmem de Oliveira Lima, Monique Ellen T.Avaliação Microbiológica de Água de Bebedouros Das Unidades de Produção de Frutos no Vale do Jaguaribe - Ce. In: Anais do 12 Congresso Latinoamericano de Microbiologia e Higiene de Alimentos - MICROAL 2014 [= Blucher Food Science Proceedings, num.1, vol.1]. São Paulo: Editora Blucher, 2014. 
utilizada a técnica de fermentação de tubos múltiplos que permite identificar o Número Mais Provável (NMP/100mL) de coliformes totais e termotolerantes, de acordo com auxílio da tabela de Hoskins. Os resultados apontaram contagens mínimas de $<3 \mathrm{NMP} / 100 \mathrm{~mL}$ em 3 amostras e as demais apresentaram valores de: $4 ; 4,3 \times 10 ; 1,5 \times 10 ; 9 ; 9,3$ $\mathrm{x} 10 ; 4,3 \times 10$ e $4 \mathrm{NMP} / 100 \mathrm{~mL}$ de coliformes totais, totalizando 7 amostras insatisfatórias, visto que a Portaria citada estabelece ausência deste microrganismo em $100 \mathrm{ml}$ da amostra. Referente à contagem de termotolerantes, os valores obtidos foram de $4 \mathrm{NMP} / 100 \mathrm{~mL}$ em 3 amostras, sendo que as demais apresentaram contagem mínima de $<3$ $\mathrm{NMP} / 100 \mathrm{~mL}$. Observou-se no final da avaliação, que somente $30 \%$ estavam dentro dos padrões e que $70 \%$ das amostras avaliadas encontraram-se impróprias para consumo. Torna-se necessário um processo de tratamento eficiente, bem como a higienização adequada desses bebedouros, além da conscientização dos colaboradores, afim de que todos possam ter acesso à água de qualidade, livre de qualquer tipo de contaminação.

Palavras-Chave: Potabilidade, Higienização, Consumo Agência de Fomento: 